The University of Maine

DigitalCommons@UMaine

7-2021

Greater belief in science predicts mask-wearing behavior during COVID-19

Morgan D. Stosic

Shelby Helwig

Mollie A. Ruben

Follow this and additional works at: https://digitalcommons.library.umaine.edu/c19_teach_doc

Part of the Higher Education Commons, History Commons, and the Medicine and Health Sciences Commons

This Article is brought to you for free and open access by DigitalCommons@UMaine. It has been accepted for inclusion in Teaching, Learning \& Research Documents by an authorized administrator of

DigitalCommons@UMaine. For more information, please contact um.library.technical.services@maine.edu. 


\title{
Greater belief in science predicts mask-wearing behavior during COVID-19
}

\author{
Morgan D. Stosic ${ }^{a, *}$, Shelby Helwig ${ }^{\text {a }}$, Mollie A. Ruben ${ }^{\mathrm{a}, \mathrm{b}}$ \\ ${ }^{\text {a }}$ Department of Psychology, University of Maine, Orono, ME, USA \\ ${ }^{\mathrm{b}}$ Center for Healthcare Organization and Implementation Research, VA Boston Healthcare System, Boston, MA, USA
}

\section{A R T I C L E I N F O}

\section{Keywords:}

Preventive behavior

Face masks

COVID-19

Belief in science

\begin{abstract}
A B S T R A C T
We investigated whether and how individual's belief in science directly impacts reported face mask wearing behavior in the United States and the mediating role of belief in mask effectiveness in preventing transmission of COVID-19 in this relationship. Mechanical Turk participants $(N=1050)$ completed measures on reported face mask wearing behavior, general beliefs in science, belief in face mask effectiveness in reducing transmission of COVID-19, and sociodemographic information. We found evidence that greater belief in science predicted greater belief in the effectiveness of face masks reducing the transmission of COVID-19, which in turn predicted more reported face mask wearing behavior in public, controlling for sociodemographic factors. We urge researchers to engage in more open science practices and science education to increase the public's belief in science and the effectiveness of masks in reducing the transmission of COVID-19 in order to increase the frequency of face mask wearing in public.
\end{abstract}

\section{Introduction}

To wear or not to wear face masks? This decision has quickly become one of the most contentious issues in the United States in response to the coronavirus (COVID-19) pandemic. Scientists and public health experts have established that masks are effective in limiting the spread of COVID-19 (Chughtai et al., 2020; Lyu \& Wehby, 2020), and several state governments have enacted mandates requiring individuals to wear masks in public (Markowitz, 2021). Still, the physical discomfort, inconvenience, and potential of masks to negatively impact face-to-face interactions have deterred countless US residents from wearing them in public. For people to engage in a preventive behavior like mask wearing despite the potential adverse experience of it, we propose that (1) people must trust and believe in science broadly; which would lead them to (2) more readily acquire knowledge about the importance of changing their behavior and risks if they do not; which would ultimately, (3) lead them to partake in more preventive behaviors.

The Belief in Science Scale (BISS; Farias et al., 2013) assesses individual differences in the belief in the value of science as an institution and science as a source of superior knowledge. Using beliefs in human causes of climate change as a proxy for general belief in science (BIS), researchers recently found that individuals who are more likely to endorse that humans impact climate change were more likely to follow COVID-19 lockdown policies and to physically distance in public
(Brzezinski et al., 2020). In this way, BIS appears to be an important individual difference that predicts preventive behavior engagement during COVID-19; however, research has not yet applied the validated BISS to face mask wearing behavior. Therefore, we aimed to examine whether BIS directly impacts reported mask wearing behavior and if belief in mask effectiveness in preventing transmission of COVID-19 is one process through which BIS impacts mask wearing behavior.

H1. We predicted that greater BIS would predict greater reported face mask wearing behavior during COVID-19.

H2. We predicted that greater BIS would predict greater belief in mask effectiveness in preventing the transmission of COVID-19.

H3. We also predicted that the relationship between BIS and mask wearing behavior would be mediated by belief in mask effectiveness in reducing the transmission of COVID-19.

\section{Method}

\subsection{Participants}

Data were collected from 1629 participants through Amazon's Mechanical Turk (MTurk) on June 3rd, 2020 through June 11th, 2020. MTurk workers who reside in the United States with a HIT Approval

\footnotetext{
* Corresponding author at: Doctoral Student in Psychology, University of Maine, 301 Little Hall, Orono, ME 04469, USA.

E-mail address: morgan.stosic@maine.edu (M.D. Stosic).
} 
Rate of $98 \%$ were compensated (US $\$ 0.50$ ) for their participation in a larger study designed to investigate differences in first impressions of individuals wearing masks (blinded for review). From this initial sample, we only included individuals who were located in the United States at present, and who passed all attention check questions $(N=1050)$ (see supplementary Table 1 for demographic information). A power analysis via Sobel Test (Zhang \& Yuan, 2015) revealed the statistical power for detecting a small to medium effects of 0.2 with a $p<.05$ with this sample size is 0.99 . Thus, this study was more than sufficiently powered (i.e., $>0.80$ ).

\subsection{Measures}

\subsubsection{Belief in science scale}

Participants completed the validated and reliable 10-item Belief in Science Scale (BISS; Dagnall et al., 2019; Farias et al., 2013) to assess the degree to which participants valued science as a source of superior knowledge. Participants were instructed to rate their agreement with items from 1 (strongly disagree) to 6 (strongly agree). An example includes: "Science is the most efficient means of attaining truth".

\subsubsection{Mask beliefs and behaviors}

Participants indicated on a 7-point scale, ranging from strongly disagree to strongly agree, the degree to which they endorsed the following statement: "Face masks provide protection from the possibility of transmitting COVID-19". Participants also indicated how frequently they wear a mask when they go out in public. The response choices provided were "Never", "Occasionally", "About half of the time", "Mostly" and "Always". This latter question served as our primary dependent variable.

\subsubsection{Sociodemographic variables}

In addition to gender, race, ethnicity, and age, participants completed questions about where they currently reside (i.e., an "urban", "suburban" or "rural" region) and their political ideology on a 7-point scale ranging 1 (extremely conservative) to 7 (extremely liberal).

\section{Results}

We tested whether a mediating relationship was supported by conducting three separate regressions controlling for age, gender, race, ethnicity, region (urban versus not urban) and political ideology (Table 1). ${ }^{1}$ Given our outcome variable was ordinal with 5 categories, we followed Liu et al.'s (2015) analytical recommendations for calculating direct and indirect effects. Our data met all the necessary assumptions for this analysis. An ordinal logistic regression provided support for $\mathrm{H} 1$; individuals who reported greater BIS were more likely to report more frequent mask wearing in public. The odds of mask wearing increased by an average of $25 \%$ for each unit increase in BIS such that individuals who scored a 6 on the BIS scale were $125 \%$ more likely to report more mask wearing than were individuals who scored a 1 [OR: 1.25; $95 \%$ CI, 1.13 to 1.39 ; Wald $(1)=17.58, p<.001$ ]. H2, examining whether greater beliefs in science predicted greater beliefs in face mask effectiveness, was tested with a general linear regression. BIS was a significant positive predictor of the belief in face mask effectiveness such that for every one unit increase in BIS, belief in face mask effectiveness increased by $0.24[b=0.24, t(1029)=5.97, p<.001]$. Finally, we performed an ordinal logistic regression to test $\mathrm{H} 3$, that the relationship between BIS and mask wearing behavior would be explained by belief in masks as effective in preventing the transmission of COVID-19. Our mediating variable of belief in face mask effectiveness was associated with an increased odds of reporting greater face mask wearing behavior

\footnotetext{
${ }^{1}$ See supplementary Table 2 for intercorrelations of the predictor variables, BIS, belief in face mask effectiveness, and sociodemographic variables.
}

Table 1

Ordinal logistic regression predicting reported face mask wearing in public.

\begin{tabular}{|c|c|c|c|c|c|}
\hline & Estimate & SE & OR $(95 \% \mathrm{CI})$ & Wald & $\mathrm{p}$ \\
\hline \multicolumn{6}{|l|}{ Total effects model } \\
\hline $\begin{array}{l}\text { Belief in science } \\
\text { (BIS) }\end{array}$ & 0.23 & 0.05 & $\begin{array}{l}1.25 \\
(1.13-1.39)\end{array}$ & 17.58 & $<.001^{* * *}$ \\
\hline Age & 0.02 & 0.01 & $\begin{array}{l}1.02 \\
(1.01-1.03)\end{array}$ & 21.63 & $<.001^{* * *}$ \\
\hline Political ideology & 0.22 & 0.04 & $\begin{array}{l}1.25 \\
(1.15-1.34)\end{array}$ & 20.73 & $<.001^{* * *}$ \\
\hline Gender $^{\mathrm{a}}$ & -0.41 & 0.13 & $\begin{array}{l}0.66 \\
(0.52-0.85)\end{array}$ & 10.85 & $.001^{* *}$ \\
\hline Race: Black ${ }^{\mathrm{b}}$ & 0.78 & 0.25 & $\begin{array}{l}2.18 \\
(1.34-3.56)\end{array}$ & 9.85 & .002 \\
\hline Race: Asian $^{\mathrm{b}}$ & 0.36 & 0.22 & $\begin{array}{l}1.43 \\
(094-2.20)\end{array}$ & 2.80 & $.094^{\dagger}$ \\
\hline Race: Other ${ }^{\mathrm{b}}$ & 0.07 & 0.28 & $\begin{array}{l}1.07 \\
(0.62-1.86)\end{array}$ & 0.06 & .811 \\
\hline Ethnicity $^{c}$ & -0.55 & 0.22 & $\begin{array}{l}0.58 \\
(0.40-0.89)\end{array}$ & 6.17 & $.013^{*}$ \\
\hline Region $^{\mathrm{d}}$ & 0.48 & 0.14 & $\begin{array}{l}1.67 \\
(1.24-2.11)\end{array}$ & 12.69 & $<.001^{* * *}$ \\
\hline \multicolumn{6}{|l|}{ Direct effects model } \\
\hline $\begin{array}{l}\text { Belief in mask } \\
\text { effectiveness }\end{array}$ & 0.60 & 0.05 & $\begin{array}{l}1.82 \\
(1.68-2.00)\end{array}$ & 179.09 & $<.001^{* * *}$ \\
\hline $\begin{array}{l}\text { Belief in science } \\
\quad \text { (BIS) }\end{array}$ & 0.12 & 0.06 & $\begin{array}{l}1.13 \\
(1.02-1.26)\end{array}$ & 4.54 & $.033^{*}$ \\
\hline Age & 0.02 & 0.01 & $\begin{array}{l}1.02 \\
(1.01-1.03)\end{array}$ & 17.56 & $<.001^{* * *}$ \\
\hline Political ideology & 0.15 & 0.04 & $\begin{array}{l}1.16 \\
(1.07-1.25)\end{array}$ & 13.38 & $<.001^{* * *}$ \\
\hline Gender $^{\mathrm{b}}$ & -0.43 & 0.13 & $\begin{array}{l}0.65 \\
(0.51-0.83)\end{array}$ & 11.47 & $.001^{* *}$ \\
\hline Race: Black ${ }^{\mathrm{c}}$ & 0.71 & 0.26 & $\begin{array}{l}2.03 \\
(1.22-3.35)\end{array}$ & 7.49 & $.006^{* *}$ \\
\hline Race: Asian $^{c}$ & 0.16 & 0.22 & $\begin{array}{l}1.17 \\
(0.76-1.82)\end{array}$ & 0.53 & .468 \\
\hline Race: Other ${ }^{c}$ & 0.20 & 0.29 & $\begin{array}{l}1.22 \\
(0.67-2.16)\end{array}$ & 0.45 & .501 \\
\hline Ethnicity $^{\mathrm{d}}$ & -0.67 & 0.23 & $\begin{array}{l}0.51 \\
(0.33-0.80)\end{array}$ & 7.04 & $.008^{* *}$ \\
\hline Region $^{\mathrm{e}}$ & 0.59 & 0.14 & $\begin{array}{l}1.80 \\
(1.41-2.38)\end{array}$ & 16.24 & $<.001^{* * *}$ \\
\hline
\end{tabular}

Note. The Total Effects Model depicts the predictive power of sociodemographic and psychosocial predictors. The Direct Effects Model depicts the predictive power of sociodemographic and psychosocial predictors with mediators (belief in mask effectivenss) included. Regression coefficients are unstandardized.

${ }^{a}$ Higher scores reflect more liberal political ideology while lower scores reflect more conservative political ideology.

${ }^{\mathrm{b}}$ Gender was coded male $=1$, female $=2$.

${ }^{\mathrm{c}}$ Race was coded as white $=1$, race specified category $=2$.

${ }^{\mathrm{d}}$ Ethnicity was coded as not Hispanic or LatinX $=1$, Hispanic or LatinX $=2$.

${ }^{\mathrm{e}}$ Region was coded as urban $=1$, not urban $=2 . N=1050$.

${ }^{\dagger} p<.10$.

* $p<.05$.

${ }^{* * *} p<.01$.

$p<.001$.

such that each unit increase in the belief that face masks are effective was associated with an $82 \%$ increase in the reported frequency of face mask wearing in public on average [OR: 1.82 ; $95 \%$ CI, 1.68 to 2.00 ; Wald $(1)=179.09, p<.001]$. Additionally, the effect of BIS on mask wearing behavior decreased when controlling for belief in face mask effectiveness, such that the odds of mask wearing only increased by an average of $13 \%$ for each unit increase in BIS (OR: 1.13; 95\% CI, 1.02 to 1.26 ; Wald $(1)=4.54, p=.033$ ). This decrease in odds was quantified by an indirect effect of BIS on reported face mask wearing behavior through belief in face mask effectiveness, $b=0.09$ (95\% CI, 0.06 to 0.12 ). Therefore, we find evidence that belief in face mask effectiveness is one process through which belief in science influences face mask wearing behavior (Fig. 1).

In addition, several of the covariates were significant predictors of 


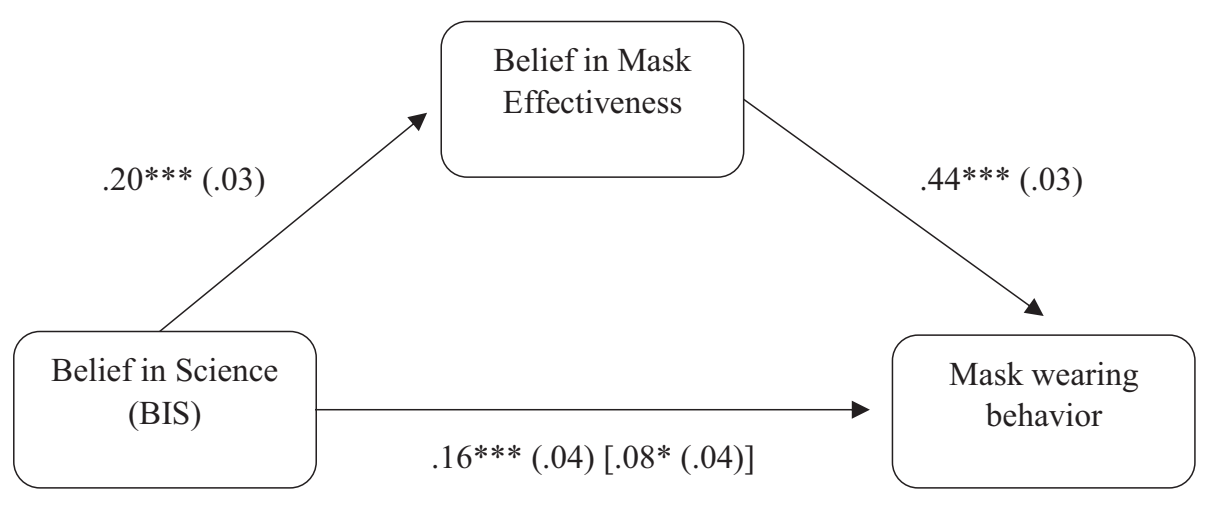

Fig. 1. Standardized Regression Coefficients for the Relationship Between Belief in Science (BIS) and Face Mask Wearing Behavior as Mediated by Belief in the Effectiveness of Face Masks from Preventing Transmission of COVID-19.

Note. The standardized regression coefficient between BIS and face mask wearing behavior, controlling for belief in the effectiveness of face masks from preventing transmission of COVID-19, is in brackets. Standard errors are reported in parentheses. ${ }^{*} p<.05$, $* * p<.01, * * * p<.001$. mask wearing. Table 1 shows that females compared to males, older adults compared to younger adults, Black individuals compared to white individuals, urban-dwellers compared to suburban or rural-dwellers, and more politically liberal individuals reported more face mask wearing behavior in public during COVID-19.

\section{Discussion}

We examined whether belief in science (BIS), a construct that measures the value one places in scientific information, predicted face mask wearing behavior and, if so, whether this relationship was mediated by one's belief in the effectiveness of face masks in reducing the transmission of COVID-19. We found support that greater BIS predicts both greater belief in the effectiveness of face masks in reducing the transmission of COVID-19 and greater reported face mask wearing in public, even when controlling for conceptually relevant socio-demographic characteristics (e.g., political ideology). We also found support for the mediating role of belief in the effectiveness of face masks reducing the transmission of COVID-19 in this relationship such that greater BIS predicted greater belief in the effectiveness of face masks reducing the transmission of COVID-19 which, in turn, predicted greater reported face mask wearing behavior in public.

Finally, in our sample, gender, age, race, ethnicity, region, and political ideology were all significant predictors of face mask wearing. This suggests that men compared to women, white individuals compared to Black individuals, non-Hispanic individuals compared to Hispanic/Latinx individuals, those in rural and suburban areas compared to urban areas, and more politically conservative individuals may benefit from targeted public health messaging about wearing face masks and about the importance of science broadly.

As countries worldwide and states begin to re-open, preventive behaviors such as following recommendations for physical distancing, washing hands frequently, and wearing face masks will be crucial in reducing the spread of COVID-19. Our findings suggest that beyond increasing the public's awareness of the effectiveness of face masks in reducing the transmission of COVID-19, we need to increase the public's belief in science in order to make information about wearing masks more effective. Without increasing the public's belief in science, public health messaging about masks may not be effective in changing behavior. These results highlight the importance of science education in shaping compliance to preventive behaviors and ultimately resilience (e. g., economically, socially, and health-wise) during health pandemics. To increase the public's belief in science, researchers should participate in open science which allows for a more transparent process and greater accessibility to research findings, report quality data only or discuss the quality of the data including limitations and generalizability, and not overstate findings. Researchers also need to build and sustain infrastructure for rapid response to public health crises and educate the public on the process and interpretation of findings including establishing ways citizen scientists can become involved (Boele-Woelki et al.,
2018). Beyond the scientific community, political figures, business leaders, and celebrities significantly influence individual's belief and trust in science, and should be encouraged to speak more openly and honestly about the importance and impact of scientific findings. By taking steps to achieve these higher societal standards, we will be more able to combat infectious diseases like COVID-19 and become better equipped to collectively fight future health crises.

\section{Author disclaimer}

The views, opinions, and content of this publication are those of the authors and do not necessarily reflect the views, opinions, or policies of the Department of Veterans Affairs or the United States Government.

\section{CRediT authorship contribution statement}

All authors contributed to the conceptualization of the research. Morgan D. Stosic: Formal analysis, Project administration, Visualization, and Writing- Original draft preparation. Shelby Helwig: Data curation, Project administration, Writing- Review and editing. Mollie A. Ruben: Methodology, Supervision, Writing- Original draft preparation.

\section{Appendix A. Sociodemographic information of the sample}

Supplementary data to this article can be found online at https://doi. org/10.1016/j.paid.2021.110769.

\section{References}

Boele-Woelki, K., Francisco, J. S., Hahn, U., \& Herz, J. (2018). How we can rebuild trust in science-And why we must. Angewandte Chemie International Edition, 57(42), 13696-13697.

Brzezinski, A., Kecht, V., Van Dijcke, D., \& Wright, A. L. (2020). Belief in science influences physical distancing in response to covid-19 lockdown policies. University of Chicago, Becker Friedman Institute for Economics Working Paper, (2020-56).

Chughtai, A. A., Seale, H., \& Macintyre, C. (2020). Effectiveness of cloth masks for protection against severe acute respiratory syndrome coronavirus 2. Emerging Infectious Diseases, 26(10), 1-5. https://doi.org/10.3201/eid2610.200948.

Dagnall, N., Denovan, A., Drinkwater, K. G., \& Parker, A. (2019). An evaluation of the belief in science scale. Frontiers in Psychology, 10.

Farias, M., Newheiser, A. K., Kahane, G., \& de Toledo, Z. (2013). Scientific faith: Belief in science increases in the face of stress and existential anxiety. Journal of Experimental Social Psychology, 49, 1210-1213.

Liu, H., Zhang, Y., \& Luo, F. (2015). Mediation analysis for ordinal outcome variables. In R. E. Millsap, et al. (Eds.), Quantitative psychology research: The 78th annual meeting of the psychometric society (pp. 429-450). Switzerland: Springer Proceedings in Mathematics and Statistics.

Lyu, W., \& Wehby, G. L. (2020). Community use of face masks and COVID-19: Evidence from a natural experiment of state mandates in the US. Health Affairs, 39(8), 1419-1425.

Markowitz, A. (2021, January 19). Does your state have a mask mandate due to coronavirus?. Retrieved January 22, 2021, from https://www.aarp.org/health/hea lthy-living/info-2020/states-mask-mandates-coronavirus.html.

Zhang, Z., \& Yuan, K.-H. (2015). WebPower: Statistical power analysis online. Retrieved from http://webpower.psychstat.org. 